\title{
Transatlantica
}

Revue d'études américaines. American Studies Journal

\section{Georges-Claude Guilbert. Carson McCullers. Amours décalées.}

Paris : Belin, 1999. 128 p.

\section{Yvette Rivière}

\section{(2) OpenEdition}

\section{Journals}

Édition électronique

URL : http://journals.openedition.org/transatlantica/718

DOI : $10.4000 /$ transatlantica.718

ISSN : 1765-2766

Éditeur

AFEA

Référence électronique

Yvette Rivière, "Georges-Claude Guilbert. Carson McCullers. Amours décalées. », Transatlantica [En ligne], 1 | 2003, mis en ligne le 05 avril 2006, consulté le 29 avril 2021. URL : http://

journals.openedition.org/transatlantica/718 ; DOI : https://doi.org/10.4000/transatlantica.718

Ce document a été généré automatiquement le 29 avril 2021.

\section{c) (i) $९$}

Transatlantica - Revue d'études américaines est mis à disposition selon les termes de la licence Creative Commons Attribution - Pas d'Utilisation Commerciale - Pas de Modification 4.0 International. 


\section{Georges-Claude Guilbert. Carson McCullers. Amours décalées.}

Paris : Belin, 1999. 128 p.

Yvette Rivière

1 Avec le recul, on redécouvre Carson McCullers et l'on tente de lui rendre justice. Après l'édition annotée par Marie-Christine Lemardeley-Cunci de nouvelles traductions de la romancière (La Pochothèque 1994) et la flamboyante biographie de Josyane Savigneau (Stock 1995), Georges-Claude Guilbert s'attache dans le format ramassé du petit Belin à la défendre contre ses détracteurs. Il glisse sur les détails biographiques qui relèvent du "voyeurisme» et se démarque des traditionnels couplets sur la solitude et le "gothique » pour cerner au plus près la voix spécifique de McCullers, son style unique et rigoureux.

2 Le sous-titre, amours décalées, joue sur le caractère unilatéral de l'amour tel qu'il se manifeste chez les différents protagonistes, puisqu'il tient davantage au regard de l'amant qu'à la nature de l'objet aimé. Mais cet amour dépasse les relations personnelles pour s'étendre à l'humanité entière sous forme de compassion envers les exclus, les marginaux (d'Eros on passe à Agape). Bien avant la reconnaissance des Droits Civiques, les Noirs sont présentés comme participant de l'humaine condition et victimes d'une terrible injustice et, bien avant les "gender studies ", McCullers insiste sur la nature double de chacun des êtres dont l'ambivalence est soulignée par la modulation des prénoms et des comportements. Nul ne mérite d'être rejeté sous prétexte qu'il n'entre pas dans un moule préformé et ne se soumet pas aux exigences de la société : éloge de la différence qui lui valut l'incompréhension des critiques les plus traditionalistes.

3 Guilbert choisit d'écarter systématiquement de sa critique les nouvelles de la romancière et sa dernière œuvre (L'Horloge sans aiguilles); il a toutefois l'habileté d'y faire référence pour étayer les thèmes ou les remarques qu'il développe. On peut regretter la présentation éclatée en quatre chapitres (avec intertitres), chacun consacré à un roman particulier, même si chacun d'eux est analysé avec franchise et avec soin. L'auteur s'attarde sur la peinture réussie de l'adolescence mais avoue sa préférence 
pour Reflets dans un ceil d'or dont, malgré les allusions freudiennes appuyées, il démontre la cohérence et l'économie musclée. Moins sensible à la dimension héroïcomique de La Ballade du café triste inspirée des contes et récits populaires, il insiste sur le côté cruel et pathétique de l'affrontement hideux et grimaçant entre spécimens de foire. L'ouvrage est bien informé, explicite les allusions et les réminiscences littéraires ; de plus, écrit dans un style vif, il a le mérite de récuser les clichés, les a priori réducteurs et de faire ressortir, par-delà le régionalisme, les résonances universelles.

INDEX

Thèmes : Recensions

\section{AUTEUR}

YVETTE RIVIÈRE

Université Paris 12 - Val de Marne 